\title{
Neuropsychological therapy: the interaction between environment, body, mind and healing
}

\author{
Volume 7 Issue I - 2017 \\ Vittorio Catalano \\ Clinical Psychologist, Italy
}

Keywords: neuropsychological therapy, environment, body, single neurons, neuropsychoanalysis, trauma

\section{Introduction}

All living beings, are dinamically related to the environment, in a constant interchange of energy that conveys informations in a perpetual open system. Therefore, everything has been prepared for what we call communication. It is expressed in many different forms, but what really interests us, is the way that humans use for assimilating, integrating and handing down all. In the early ' 80 s, some researches focused on the study of the premotor cortex of monkeys, revealed the existence of neurons (mirror neurons) activated when monkeys were performing actions (not of individual movements, but finalized motor acts). The team at the University of Parma, directed by Giacomo Rizzolatti ${ }^{1}$ have studied in an experiment, the deputies neurons that have control of hand movements (eg. To collect or handle objects), the study involved the premotor ventral cortex (area F5) of a macaque. The registration of cortical activity to the level of single neurons, occurred while the animal was taking a portion of food, has allowed the monitoring of specific movements. With much surprise of the experimenters, was recorded the activity of some motor neurons in the macaque, that motionless was watching one of the researchers taking a banana from the fruit bowl. The monkey was motionless, but his motor neurons have reacted to the view of the action conducted by the experimenter. Subsequent experimental measurements, initially considered inaccurate, have confirmed what was been initially observed. Other subsequent experimental tests have indicated the involvement of other cortical areas, drawing the formation of a real neural system composed of cortico-cortical circuits of sensory integration in the motor cortex and premotor cortex of the frontal lobe, and also the parieto-temporal cortex. The correlation between the concept of memory, the concept of mental image and mental association, seems today something of obvious and evident, but what I want to emphasize here and now, is the evidence that the organisms assimilate and retain information, for reuse it during a subsequent interaction with the environment. This last concept is fundamental when we are talking about trauma in clinical neuropsychology. Neuropsychoanalysis, is focused, on the existing contact points between the modern concept of implicit memory (cognitive concept), and the concept of the unconscious (psychoanalytical concept): these different views, would be united, from the specific capacity to equip with continuity and meaning reality, influencing behavior, guiding and motivating the individual's actions, without entailing the use of awareness/consciousness. Moreover, they studied, the short and long term effects that difficult and traumatic experiences, such as early separation from the mother, repeated abuse, stress, produce on the development of the brain, and how this is reflected on the overall development of the person. In genetic terms the development of the brain is the product of the effects that the experiences cause on the expression of the genetic potential Kandel. ${ }^{2}$ This means that our experiences affect directly the way in which genes are expressed
Correspondence: Vittorio Catalano, Clinical Psychologist, Italy, Email maveril333@yahoo.it

Received: June 21, 2016 | Published: January 05, 2017

through the protein synthesis (transcription), and may therefore have direct effects on the processes that lead to the development of neuronal circuits, promoting the formation of new synaptic connections, changing the preexisting or, facilitating their elimination. In the brain, stressful situations are associated and correlated to the secretion of corticosteroid hormones which have direct effects on gene expression. ${ }^{3}$ In children victims of repeated maltreatment at early age, can be found brain damage that concern, over to the hippocampus, the autonomous nervous system, the hypothalamus-hypophysealadrenocortical axis, the neuro-immune system. Chronic stress, causes excessive growth, of the regions of the brain involved in the anxiety and fear responses (amygdala), and a contemporary underdevelopment of neural connections in other brain regions. ${ }^{4,5}$ A study highlights an important role of mirror neurons in the motor deficits recovery: their activation during the observation of a movement, acts on the motor cortex restoring the functionality of inactive areas, as well as if the movement had actually been accomplished. In their work the researchers were focused on the possibility of recover the ability to move limbs after a long period of inactivity and without performing directed motor actions.

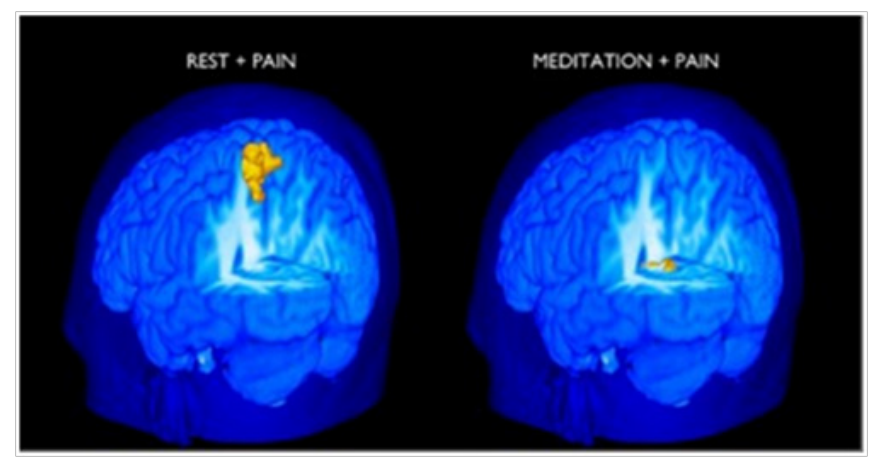

In fact, a long physical inactivity, caused by immobilization or a non-use of a limb, cause in the brain a reduced functioning of 
the motor cortex, which can be restored through movement, of the stopped limb. The researchers have showed that this recovery can happen also only through the observation of the same movement. The work of Prof.Kandel has illuminated some of the basic molecular mechanisms that explain learning and memory in animals and is central to understanding not only the concept of normal memory but also the disorders that afflict the memory as PTSD. Dr. Kandel and his colleagues have identified a molecule, a prion protein, called CPEB, which plays a key role in maintaining long-term memory in Mice and Aplysia (sea snail). A mouse was trained to memorize a way to navigate through a labyrinth. Eliminated from the mice, the homologous CPEB gene, called CPEB3, this has eliminated the maintenance of long-term memory that has caused the loss of information to the mice on how to navigate in the labyrinth. Consequently, it is increasingly clear that neuropsychological therapies based on 'mind-body-world interaction as Meditation, Imagery, Mindfulness are able not only to change emotional states, but are also able to change the structure of our brain (Lazar, Denninger, Vago), for example, Mindfulness helps to reduce the volume of the amygdala (Lazar), the brain region devoted to the management of fear. The participants in the study have showed, also a significant decrease in stress during the practice period. The research group of Eileen Luders, University of California, Los Angeles, has found that meditation helps to preserve gray matter in the brain, the tissue that contains neurons. Perla Kaliman Institute for biomedical research of Barcelona has observed like one day of intense meditation reduces the activity of genes that regulate inflammation and alter the enzymatic functions involved in the genetic operation. So as already Professor Benson had expressed: the relaxation response (RR) is a state elicited from any practice mind-body, including yoga, meditation, prayer, and is conceptually the opposite of the stress response is also accompanied by physiological changes, such as a decrease in heart rate and decrease in respiratory rate.

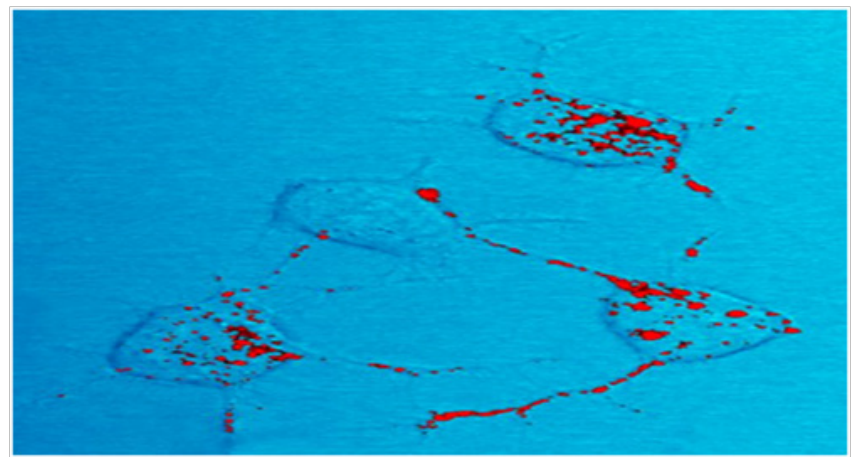

\section{Psychology of trauma and healing with imaginative meditation}

Trauma is an internal expression of response to the pain of a wound, this pain can be hidden, and create a silent and unconscious suffering in survivors. The same pain, can also be detected, from survivors, in singular ways which trigger memory of trauma, and suffering. All people have a deep desire to be loved and cared for, including survivors. The pain can become chronic and debilitating, because of a failure of traumatic event processing. Some survivors may be aware of their pain, experiencing deep sadness and anger, for their inability to react. This causes deterioration in the quality of affective and interpersonal relationships.After all, personal growth methods are painful, and humans are wired to avoid pain and seek pleasure. ${ }^{6}$ Most of the survivors, if they are not in crisis, have not care what happened: people, places, things, and relationships that have shaped their long life. A rule in our universe, asserts that nothing ever stays the same. All living matter, is in a process of growth or regression phase..$^{7-18}$ The recovery process with the identification, is related to a higher force, which manifests itself as soon as you include its beneficial power. This understanding, in conjunction with the application of "temporal tested principles," gets in touch with the "power." As you continue to apply the principles and understanding, and deepening the meditative path, you can explain yourself, the new individual dimension, and the ways in which it manifests itself in your personal life journey. At this point, you have experienced a spiritual awakening, sensory, and personal in yourself. This, it happened slowly and gradually, after a patient and structured work: if you have slept for a long time, you need a long time to wake up, can not happen during one night. ${ }^{6}$

\section{Acknowledgments}

None.

\section{Conflicts of interest}

Author declares there are no conflicts of interest.

\section{Funding}

None.

\section{References}

1. Rizzolatti G, Fadiga L, Gallese V, et al. Premotor cortex and the recognition of motor actions. Brain Res Cogn Brain Res. 1996;3(2):131-141.

2. Kandel ER. Genes, nerve cells, and remembrance of things past. $J$ Neuropsychiatry Clin Neurosci. 1989;1(2):103-125.

3. Kandel ER. A new intellectual framework for psychiatry. Am $J$ Psychiatry. 1998;155(4):457-469.

4. Bremner JD, Narayan M. The effect of stress on memory and the hippocampus throughout the life cycle: Implication for child development and aging. Dev Psychopathol . 1998;10(4):871-885.

5. Perry BD, Pollard RA, Blakely TL, et al. Childhood trauma, the neurobiology of adaptation, and use dependent development of the brain: How states become traits. Infant Mental Health Journal. 1995;16(4):271-291.

6. Rivka AE. Trauma and Trasformation: a 12-steps guide. 2013.

7. Gallese V, Fadiga L, Fogassi L, et al. Action recognition in the premotor cortex. Brain. 1996;119(Pt 2):593-609.

8. Pellegrino G, Fadiga L, Fogassi L, et al. Understanding motor events: a neurophysiological study. Exp Brain Res. 1992;91(1):176-180.

9. Rizzolatti G, Craighero L. The mirror-neuron system. AnnuRevNeurosci. 2004;27:169-192.

10. www.neuroscienze.net/?p=1560

11. Milner B, Squire LR, Kandel ER. Cognitive neuroscience and the study of memory Neuron. 1998;20(3):445-468

12. Buckner RL, Petersen SE, Ojemann JG, et al. Functional anatomical studies of explicit and implicit memory retrieval tasks. J Neurosci. 1995; 15(1 Pt 1):12-29.

13. http://blogs.plos.org/

14. http://www.estense.com/

15. http://www.huffingtonpost.it/2014/10/31/meditazione-mindfulnessrevolution n 6082230.html

16. http://newsroom.ucla.edu/releases/forever-young-meditation-mightslow-the-age-related-loss-of-gray-matter-in-the-brain-say-uclaresearchers

17. http://www.huffingtonpost.com/2013/12/09/mindfulness-meditationgene-expression_n_4391871.html

18. http://hms.harvard.edu/videos/now-and-zen 